\title{
PENGAMATAN PEMIJAHAN ALAMI, PERKEMBANGAN EMBRIO DAN LARVA IKAN KERAPU BATIK, Epinephelus microdon DALAM BAK TERKONTROL
}

\author{
Bejo Slamet $^{*}$ dan Tridjoko*)
}

\begin{abstract}
ABSTRAK
Kerapu batik, Epinephelus microdon telah berhasil dipijahkan di Loka Penelitian Perikanan Pantai Gondol. Wadah pemeliharaan berupa bak beton volume $20 \mathrm{~m}^{3}$ yang diisi 16 ekor induk (4 jantan dan 12 betina) dengan ukuran bobot 500-2500 gram, pergantian air 400\%/hari dan pemberian pakan dengan ikan dan cumi-cumi 3-5\% biomassa per hari. Pemijahan terjadi pada bulan Okober, November dan Desember dengan total jumlah telur 7.790 .000 butir dan rasio penetasan $65-85 \%$. Dari hasil pengamatan perkembangan embrio didapatkan waktu inkubasi telur 18 jam 30 menit pada suhu $27-29^{\circ} \mathrm{C}$. Hasil pengamatan perkembangan larva didapatkan bahwa pertumbuhan panjang total larva cepat pada 24 jam pertama dan menurun sampai umur 10 hari, kemudian pertumbuhan meningkat secara eksponensial. Larva yang baru menetas dengan panjang total $1,52 \pm 0,15 \mathrm{~mm}$, mengandung kuning telur yang besar $(843 \pm 35,1 \mu \mathrm{m})$ tetapi penyerapannya sangat cepat dan habis pada 76-85 jam setelah menetas (SM), sedangkan butir minyak habis terserap pada 91-95 jam SM. Mulut mulai terbuka pada 55-59 jam SM dan mulai makan pada 61-85 jam SM. Jumlah rotifer dalam lambung larva meningkat dengan pertambahan panjang larva dan stabil 24 ind./larva pada umur 12-15 hari.
\end{abstract}

ABSTRACT: Observation on natural spawning, embryonic and larval development of grouper (Epinephelus microdon) in captivity. By: Bejo Slamet and Tridjoko.

Natural spawning of grouper (Epinephelus microdon) was successfully achieved in Gondol Research Station for Coastal Fisheries. Sixteen fishes stocked in concrete tank of $20 \mathrm{~m}^{3}$ in volume with water exchange rate of about 400\% per day and fed with fish and squid 3-5\% biomass per day. The broodstock spawned in October, November and December with total number of eggs about 7.790 .000 and hatching rate of $65.85 \%$. Eggs diameter was $880-885 \mu \mathrm{m}$ with oil globule diameter of $170-181 \mu \mathrm{m}$. The embryonic development stages was observed and incubation time of egg was about 18 hours 30 minutes in temperature of $27-29^{\prime \prime} \mathrm{C}$. Observation on larval development showed that the larval grew in total length rapidly in the first 24 hours after hatching $(A H)$, followed by levelled off growth till day 10 and then grew exponentially. The newly hatched larvae with total length of $1.52 \pm 0.15 \mathrm{~mm}$ had a good reserve of yolk $(880-885 \mu \mathrm{m}$ in diameter), but it was precipitately consumed and exhausted by $76-85$ hours AH. The oil globule resorption was completed at 91-95 $\mathrm{h} \mathrm{AH}$. The mouth started opening at 55-59 h AH and first feeding incidence was evident at 61-85 $\mathrm{h} \mathrm{AH}$. The number of rotifers ingested increased gradualy and reached a stable lovel at about 24 ind. /larvae at day 12-15. KEYWORD: natural spawning, embryonic and larval development, Epinephelus
microdon.

\section{PENDAHULUAN}

Ikan kerapu batik, Epinephelus microdon merupakan satu di antara jenis kerapu yang mempunyai nilai ekonomis dan harga tinggi di pasar Asia seperti Hongkong, China, Jepang dan Singapura. Harga per kilogram dalam kondisi hidup (ukuran konsumsi) di Indonesia berkisar antara
Rp40.000-Rp50.000. Permintaan pasar internasional akan jenis kerapu ini makin meningkat dan merangsang penangkapan berlebihan, di mana ukuran konsumsi ikan ini pada ukuran bobot $0,5-1,5 \mathrm{~kg}$, sedangkan ukuran bobot $1 \mathrm{~kg}$ ke atas sudah merupakan ukuran induk. Hal ini dikhawatirkan akan mengancam kelestarian populasinya di alam. Kendala utama pada usaha

\footnotetext{
Peneliti pada Loka Penelitian Perikanan Pantai Gondol - Bali
} 
budidayanya adalah kurang tersedianya benih dalam jumlah cukup dan berkesinambungan karena masih mengandalkan benih alam.

Penelitian pemeliharaan larva beberapa jenis ikan kerapu telah dilakukan antara lain Epinephelus akaara (Ukawa et al.. 1966; Tseng \& Ho, 1979), E. amblyc(phalus (Tseng \& Chan, 1985), $E$. salmoides (Hamanto et al., 1986; Huang e't al., 1986; Lin et al., 1986), E. tauvina (Hussain et al., 1975; Chen et al., 1977; Hussain \& Higuchi, 1980) dan kerapu macan, E. fuscoguttatus (Supriatna \& Kohno, 1990). Dari informasi beberapa hasil penelitian tersebut di atas menyebutkan terjadinya tingkat kematian yang tinggi pada stadia awal yaitu umur 4-6 hari. Tingkat kematian yang tinggi pada stadia awal larva menurut Hussain \& Higuchi (1980) disebabkan karena ukuran pakan awal yang kurang sesuai. Pendapat lain menyebutkan masa kritis pada stadia awal larva berhubungan dengan saat pergantian sumber nutrisi dari dalam (endogenous) ke nutrisi dari luar (exogenous) (Hunter, 1980; Roger \& Westin, 1981). Pemijahan jenis kerapu batik di Jepang pertama kali dilaporkan oleh Tawada (1989).

Penelitian bertujuan untuk mengetahui beberapa aspek pemijahan seperti waktu pemijahan, jumlah, diameter, derajat pembuahan dan derajat penetasan telur; perkembangan embrio dan aspek perkembangan larva antara lain perkembangan morfologi, penyerapan kuning telur (yolk) dan butir minyak (oil globule) serta tabiat makan yang merupakan data dasar untuk menunjang usaha perbenihannya.

\section{BAHAN DAN METODE}

\section{Pengamatan Pemijahan dan Per- kembangan Embrio}

Percobaan ini dilakukan di Loka Penelitian Perikanan Pantai Gondol Bali selama satu tahun yaitu dari bulan Januari sampai dengan Desember 1996. Sebagai wadah pemeliharaan induk bak beton berbentuk segi empat dengan ukuran $3 \times 7$ $\mathbf{m}^{2}$, kedalaman air $1,25 \mathrm{~m}$ dan diisi 16 ekor induk kerapu batik. Induk kerapu batik yang digunakan dengan kisaran bobot hetina antara 500-1.800 gram/ekor dan jantan antara 1.900-2.500 gram/ ekor dan panjang total antara $32-51 \mathrm{~cm}$ (Tabel 1). Bak pemeliharaan induk dilengkapi dengan aerasi sebagai sumber oksigen dan pergantian air sebanyak kurang lebih $400 \% /$ hari dengan sistem air mengalir. Selama pemeliharaan induk diberi pakan segar, ikan rucah dan cumi-cumi sebanyak $3-5 \%$ dari bobot total ikan/hari dan juga ditambahkan vitamin mix. Setiap hari dilakukan penyiponan terhadap kotoran dan sisa makanan yang mengendap di dasar tangki. Setiap bulan sekali induk direndam air payau (5 ppt) selama 30-60 menit untuk menghilangkan parasit dan bak pemeliharaan dibersihkan untuk meng. hindari dan menanggulangi adanya berbagai kemungkinan serangan penyakit. Pada pipa pembuangan air dipasang jaring kecil berbentuk segi empat ukuran panjang: $75 \mathrm{~cm}$, lebar $50 \mathrm{~cm}$ tinggi $50 \mathrm{~cm}$ sebagai tempat penampungan telur (egg collector) yang terbuat dari nilon monofilamen dengan ukuran mata jaring (mesh size) $400 \mu \mathrm{m}$.

Untuk mengetahui hasil pemijahan (spawning), maka setiap pagi jam 07:30 dilakukan pengamatan pada tempat penampungan telur. Selanjutnya dilihat kualitas dan kuantitas telur tersebut: jumlah telur yang tenggelam, jumlah telur yang mengapung, jumlah total telur yang dihasilkan dan daya tetas telur.

Untuk pengamatan perkembangan embrio dilakukan dengan pengambilan sampel telur sebanyak 50 butir dari saat memijah setiap satu jam hingga telur menetas. Pengamatan telur dan pengambilan foto dilakukan di bawah mikroskop.

\section{Pengamatan Perkembangan Larva}

Larva yang digunakan berasal dari penetasan telur hasil pemijahan alami dalam bak beton volume $20 \mathrm{~m}^{3}$. Larva yang baru menetas dipindahkan ke bak beton volume $5 \mathrm{~m}^{3}$ yang diisi air laut yang telah difilter sebanyak $4 \mathrm{~m}^{3}$ dan diaerasi, Penebaran larva dengan kepadatan 30 ekor/liter. Mulai larva umur dua hari diberi pakan rotifer (Brachionus plicatilis) tipe SS dan mulai umur tujuh hari diberi rotifer tipe $\mathbf{S}$. Fitoplankton Chlorella sp. ditambahkan ke dalam bak pemeliharaan larva untuk menekan amonia yang berlebihan dan sebagai pakan rotifer yang tersisa dalam bak pemeliharaan larva. Mulai larva umur delapan hari dilakukan penyiponan terhadap kotoran yang ada di dasar bak. Pergantian air dilakukan sebanyak $20 \%$ dari total volume. Selanjutnya penyiponan dilakukan setiap dua hari dan pergantian air ditingkatkan persentasenya hingga $50 \%$. 
Tabel 1. Ukuran induk kerapu batik (Epinephelus microdon) yang digunakan untuk penelitian

Table 1. Size of the grouper (Epinephelus microdon) used in the experiment.

\begin{tabular}{cccc}
\hline $\begin{array}{c}\text { Induk } \\
\text { Broodstock }\end{array}$ & $\begin{array}{c}\text { Bobot tubuh } \\
\text { Body weight } \\
(\mathbf{g})\end{array}$ & $\begin{array}{c}\text { Panjang total } \\
\text { Total length } \\
(\mathbf{c m})\end{array}$ & $\begin{array}{c}\text { Kelamin } \\
\text { Sex }\end{array}$ \\
\hline 1 & 2,500 & 51.0 & $\mathrm{M}$ \\
2 & 2,050 & 48.0 & $\mathrm{M}$ \\
3 & 1,900 & 45.0 & $\mathrm{M}$ \\
4 & 1,900 & 44.0 & $\mathrm{M}$ \\
5 & 1,800 & 43.0 & $\mathrm{~F}$ \\
6 & 1,700 & 42.5 & $\mathrm{~F}$ \\
7 & 1,600 & 40.5 & $\mathrm{~F}$ \\
8 & 1,450 & 39.5 & $\mathrm{~F}$ \\
9 & 1,350 & 39.0 & $\mathrm{~F}$ \\
10 & 1,100 & 38.5 & $\mathrm{~F}$ \\
11 & 1,050 & 38.0 & $\mathrm{~F}$ \\
12 & 500 & 34.0 & $\mathrm{~F}$ \\
13 & 650 & 33.5 & $\mathrm{~F}$ \\
14 & 550 & 32.0 & $\mathrm{~F}$ \\
15 & 500 & 32.5 & $\mathrm{~F}$ \\
16 & 950 & 38.0 & $\mathrm{~F}$ \\
\hline
\end{tabular}

$\mathrm{M}=\operatorname{Jantan}($ Male $)$

$\mathrm{F}=$ Betina $\left(F^{\prime}\right.$ male $)$

Pengambilan sampel larva dilakukan mulai saat larva baru menetas sampai umur 30 hari. Pada larva umur 0-3 hari pengambilan sampel dilakukan setiap tiga jam sedangkan pada umur 4-6 hari dilakukan tiga kali sehari pada pagi, siang dan sore hari masing-masing sebanyak 20 ekor. Pengamatan di bawah mikroskop yang dilengkapi dengan mikrometer dilakukan terhadap panjang total, diameter kuning telur dan butir minyak, lebar bukaan mulut, perkembangan organ tubuh dan mulai umur tiga hari diamati pula isi lambungnya. Pengamatan isi lambung dilakukan dengan pembedahan dan penghitungan jumlah dan ukuran rotifer dalam lambung di bawah mikroskop. Pada larva umur 7-30 hari pengambilan sampel dilakukan sehari sekali pada jam 10.00-13.00 sebanyak 10 ekor. Mulai larva umur delapan hari dilakukan pula pengukuran panjang duri sirip punggung (dorsal spine) dan sirip dada (pectoral spine).

\section{HASIL DAN PEMBAHASAN}

\section{Pemijahan}

Pemijahan terjadi setelah dipelihara dalam bak $20 \mathrm{~m}^{3}$ selama sembilan bulan. Dari jumlah 16 ekor induk ikan kerapu batik terdapat empat ekor jantan dan 12 ekor betina. Jadi jumlah perbandingan antara induk jantan dan betina adalah sekitar 1:3. Keberhasilan pemijahan tersebut menunjukkan bahwa perbandingan jumlah jantan dan betina dalam penelitian ini cukup baik untuk ikan kerapu batik. Hal tersebut telah berhasil 
dilakukan pada jenis ikan kerapu lain seperti kerapu lumpur (Epinephelus suillus), kerapu macan (E. fuscoguttatus) (Mayunar et al., 1993) dan kerapu bebek (Cromileptes altivelis) (Tridjoko et al., 1996).

Ikan kerapu bersifat Protogynous hermaphrodite (Heemstra \& Randall, 1993) di mana betina dewasa akan mengalami perubahan kelamin (change of sex) menjadi jantan. Namun perubahan kelamin yang terjadi pada ikan kerapu batik belum diteliti, dan sedang diteliti di Loka Penelitian Perikanan Pantai Gondol - Bali. Perubahan kelamin betina menjadi jantan tergantung ukuran dan jenis. Misalnya pada $E$. tauvina (Chen et al., 1977) panjang betina yang matang adalah $45-50 \mathrm{~cm}$ (sebagian besar $50-70$ cm) dan transisi gonadnya terjadi pada panjang total (TL) $66.72 \mathrm{~cm}$ dan testis mulai matang pada TL $74 \mathrm{~cm}$ atau bobot tubuh (BW) $11 \mathrm{~kg}$. Sedangkan pada $E$. morio terjadi pada TL $71,5 \mathrm{~cm}, E$. guaza TL $89 \mathrm{~cm}$ dan E. maculatus terjadi pada TL $44 \mathrm{~cm}$ (Shapiro, 1987).

Hasil pemijahan alami kerapu batik ( $E$. microdon), secara rinci tertera pada Tabel 2 .
Pemijahan kerapu batik terjadi pada tengah malam hari yaitu jam 12.30 pada suhu air antara $27,3-30,5^{\circ} \mathrm{C}$ dan salinitas $32-33 \mathrm{ppt}$. Ukuran diameter telur antara $880-885 \mu \mathrm{m}$. Kualitas telur merupakan refleksi dari komposisi kimia kuning telur yang dipengaruhi oleh keadaan nutrisi pakan dan kondisi induk. Menurut Purdom (1979) dalam Hardjamulia (1988), ukuran telur dapat bersifat genetis yang ditunjukkan oleh kecilnya variasi ukuran telur atau sebagai akibat dari pengaruh makanan dan lingkungan. Ukuran telur mempunyai peranan terhadap sintasan dan pertumbuhan post larva yang dihasilkan.

Pada Tabel 2 terlihat bahwa pemijahan terjadi tiga bulan berturut-turut dengan jumlah total telur yang semakin banyak yaitu 475.000 butir pada bulan Oktober, 2.465 .000 butir pada November dan 4.950 .000 butir pada bulan Desember. Hal ini disebabkan karena semakin banyaknya jumlah induk betina yang memijah, di mana dari hasil pemeriksaan diameter telur dalam gonad (oocyt) jumlah induk yang matang pada bulan Oktober tiga ekor, November 10 ekor dan Desem. ber 12 ekor. Dari data tersebut diperkirakan fekunditas tiap induk kerapu batik betina ber-

Tabel 2. Hasil pengamatan jumlah telur, persentase telur yang mengapung, rasio pembuahan dan penetasan telur ikan kerapu batik (E. microdon).

Table 2. Observation on total number of egg, floating egg, sinking egg and hatching rate of grouper $(\mathrm{E}$. microdon).

\begin{tabular}{cccccc}
\hline $\begin{array}{c}\text { Tanggal } \\
\text { Date }\end{array}$ & $\begin{array}{c}\text { Jumlah telur } \\
\text { Number } \\
\text { of eggs }\end{array}$ & $\begin{array}{c}\text { Telur } \\
\text { mengapung } \\
\text { Floating eggs }\end{array}$ & $\begin{array}{c}\text { Rasio } \\
\text { pembuahan } \\
\text { Fertilization } \\
\text { rate } \\
(\%)\end{array}$ & $\begin{array}{c}\text { Diameter } \\
\text { telur } \\
\text { Diemeter of } \\
\text { eggs } \\
(\boldsymbol{\mu m})\end{array}$ & $\begin{array}{c}\text { Derajat } \\
\text { Penetasan } \\
\text { Hatching } \\
\text { rate } \\
(\%)\end{array}$ \\
\hline $08-10-1996$ & 125.000 & 70.0 & 82.0 & 885 & 65.0 \\
$09-10-1996$ & 350.000 & 85.0 & 88.0 & 880 & 75.0 \\
$07-11-1996$ & 35.000 & 95.0 & 98.0 & 880 & 82.0 \\
$08-11-1996$ & 30.000 & 90.0 & 92.0 & 885 & 80.0 \\
$09-11-1996$ & 1.800 .000 & 85.0 & 92.0 & 882 & 82.0 \\
$10-11-1996$ & 600.000 & 82.0 & 88.0 & 880 & 85.0 \\
$06-12-1996$ & 150.000 & 85.0 & 88.0 & 885 & 75.0 \\
$07-12-1996$ & 1.200 .000 & 80.0 & 87.0 & 880 & 78.0 \\
$08-12-1996$ & 2.500 .000 & 75.0 & 85.0 & 880 & 72.0 \\
$09-12-1996$ & 1.100 .000 & 80.0 & 85.0 & 880 & 75.0 \\
\hline
\end{tabular}


kisar antara 150.000-500.000 butir. Shapiro (1987) melaporkan bahwa jumlah telur yang dihasilkan oleh satu ekor induk betina tergantung pada ukuran bobot dan spesiesnya, misalnya E. guttatus 900.000-3.365.000, E. morio 312.000-5.735.000 dan E. diachantus 63.000233.000. Bouin \& Siaul (1983) menyatakan telur yang dihasilkan oleh induk betina bertambah sejalan dengan meningkatnya bobot induk.

Hasil pengamatan derajat pembuahan dan penetasan telur (Tabel 2) adalah hampir sama dan masih dalam kisaran yang baik, hal ini menunjukkan jumlah induk jantan masih cukup untuk membuahi induk betina yang bertelur.

Musim pemijahan ikan kerapu sangat dipengaruhi oleh tempat di mana ikan itu hidup dan juga oleh jenisnya serta fase bulan. Seperti kerapu macan (E. fuscoguttatus) diduga musim pemijahannya terjadi hampir sepanjang tahun tetapi puncaknya terjadi pada bulan Agustus dan November (Mayunar et al., 1991; Budileksono \& Sofyan, 1993). Sedangkan puncak musim pemijahan kakap putih terjadi pada bulan NovemberJanuari (Slamet et al., 1991). Bila dilihat dari fase bulan, ikan kerapu batik memijah sekitar bulan (lunar) baru yaitu dari satu hari sebelum bulan baru sampai tiga hari setelah bulan baru. Hasil ini hampir sama dengan kerapu macan, di mana menurut Mayunar et al. (1991) kerapu macan, $E$. fuscoguttatus memijah tiga hari menjelang sampai dua hari setelah bulan baru.

\section{Perkembangan Embrio}

Hasil pengamatan terhadap telur yang dibuahi sampai menetas pada kisaran suhu media $27-29^{\circ} \mathrm{C}$ dan salinitas $33 \mathrm{ppt}$, disajikan pada Gambar 1. Telur kerapu batik yang dibuahi terdapat gelembung minyak berdiameter antara $170 \mu \mathrm{m}-180 \mu \mathrm{m}$. Pembelahan sel telur dari satu sel ke dua sel terjadi pada 25 menit setelah pemijahan (SP), kemudian empat sel pada 30 menit SP. Sel-sel telur terus membelah menjadi delapan sel (Gambar 1A), kemudian 16 sel terjadi 65 menit SP. Selanjutnya menjadi $32 \mathrm{sel}, 64 \mathrm{sel}$ terjadi pada 1 jam 25 menit SP. Kemudian menjadi 128 sel (Gambar 1B) pada 1 jam 50 menit SP.

Fase morula terbentuk pada 2 jam 05 menit SP dan fase blastula pada 3 jam 30 menit SP, sedangkan fase gastrula terjadi pada 4 jam 30 menit SP (Gambar 1C). Selanjutnya fase neurola terjadi pada 7 jam 10 menit SP di mana pelindung embrio mulai terbentuk (Gambar 1D). Fase pembentukan kepala dan ekor terjadi pada 9 jam 30 menit SP. Fase pembentukan mata terjadi pada 10 jam 20 menit SP serta pembentukan sistem saluran pencernaan terjadi pada $11 \mathrm{jam}$ 10 menit SP. Jantung mulai aktif berdenyut pada 12 jam 10 menit SP. Selanjutnya embrio akan terbentuk sempurna dan terjadi pergerakanpergerakan dan siap akan menetas (Gambar 1E), selanjutnya telur menetas pada 18 jam 30 menit SP. Larva yang baru menetas mempunyai ukuran panjang total $1,52 \mathrm{~mm}$. Dibandingkan dengan jenis kerapu lain misalnya $E$. malabaricus mulai telur dibuahi hingga menetas memerlukan waktu yang hampir sama yaitu antara 17-19 jam pada suhu $26-29^{\circ} \mathrm{C}$ (Ruangpanit et al., 1993). Demikian juga yang terjadi pada ikan kakap (Lates calcarifer), Maneewongsa \& Tattanon (1982) mengemukakan bahwa saat telur dibuahi hingga menetas membutuhkan waktu 17 jam 30 menit pada suhu antara $27-29^{\circ} \mathrm{C}$ dan salinitas $33 \mathrm{ppt}$. Namun pada ikan kakap mata kucing (Psammoperca waigiensis) telur menetas 13 jam setelah pemijahan pada suhu inkubasi $27-29^{\circ} \mathrm{C}$ dan salinitas 33 ppt (Sunyoto et al., 1993). Lain halnya dengan kerapu sunu (Plectropomus leopardus) pada kisaran suhu $23,1-23,7^{0} \mathrm{C}$ telur baru bisa menetas 26 jam 40 menit setelah pembuahan (Masume et al., 1993).

\section{Perkembangan Larva}

Perkembangan morfologi larva antara lain panjang total, duri sirip punggung dan duri sirip dada dapat dilihat pada Gambar 2. Penyerapan kuning telur dan butir minyak pada Gambar 3 dan tabiat makan pada Gambar 4. Larva kerapu bebek yang baru menetas (D-0) dengan panjang total 1,52 $\pm 0,15 \mathrm{~mm}$, mempunyai kuning telur yang besar yaitu dengan ukuran panjang $843 \pm$ $35,1 \mu \mathrm{m}$ dan tinggi $780 \pm 32,5 \mu \mathrm{m}$, sedangkan butir minyak dengan diameter $176 \pm 5,29 \mu \mathrm{m}$ yang berlokasi di bagian ujung belakang kuning telur (Gambar 5A). Hasil ini hampir sama dengan jenis kerapu lain, di mana panjang total larva yang baru menetas pada kerapu macan ( $E$. fuscoguttatus) $1,34 \pm 0,053 \mathrm{~mm}$ (Kohno et al., 1990); E. akaara 1,45-1,50 mm (Ukawa et al., 1966); 1.57 mm (Tseng \& Ho, 1979); E. amblycephalus 2,0 mm ('Tseng \& Chan, 1985); E. salmoides 1,50-1,92 mm (Huang et al., 1986); $E$. 
tauvina 1,4-1,5 mm (Hussain et al., 1975); $1,7 \mathrm{~mm}$ (Chen et al., 1977); 2,0-2,4 mm (Hussain \& Higuchi, 1980); kerapu bebek, Cromileptes altivelis $1,74 \pm 0,056 \mu \mathrm{m}$. Calon saluran pencernaan mulai terlihat pada 5 jam SM. Dari pengamatan suhu media pemeliharaan larva didapatkan antara $27-29^{\circ} \mathrm{C}$.
Pada larva umur 1 hari (D-1) (Gambar 5B) saluran pencernaan sudah mulai terlihat, tetapi mulut dan anus masih tertutup; sudah terbentuk mata (optic vesicle) tetapi belum terjadi pigmentasi dan melanofore belum terbentuk. Penyerapan kuning telur D-1 berjalan cepat, di mana pada 16 jam setelah menetas (SM) (D-1 malam)
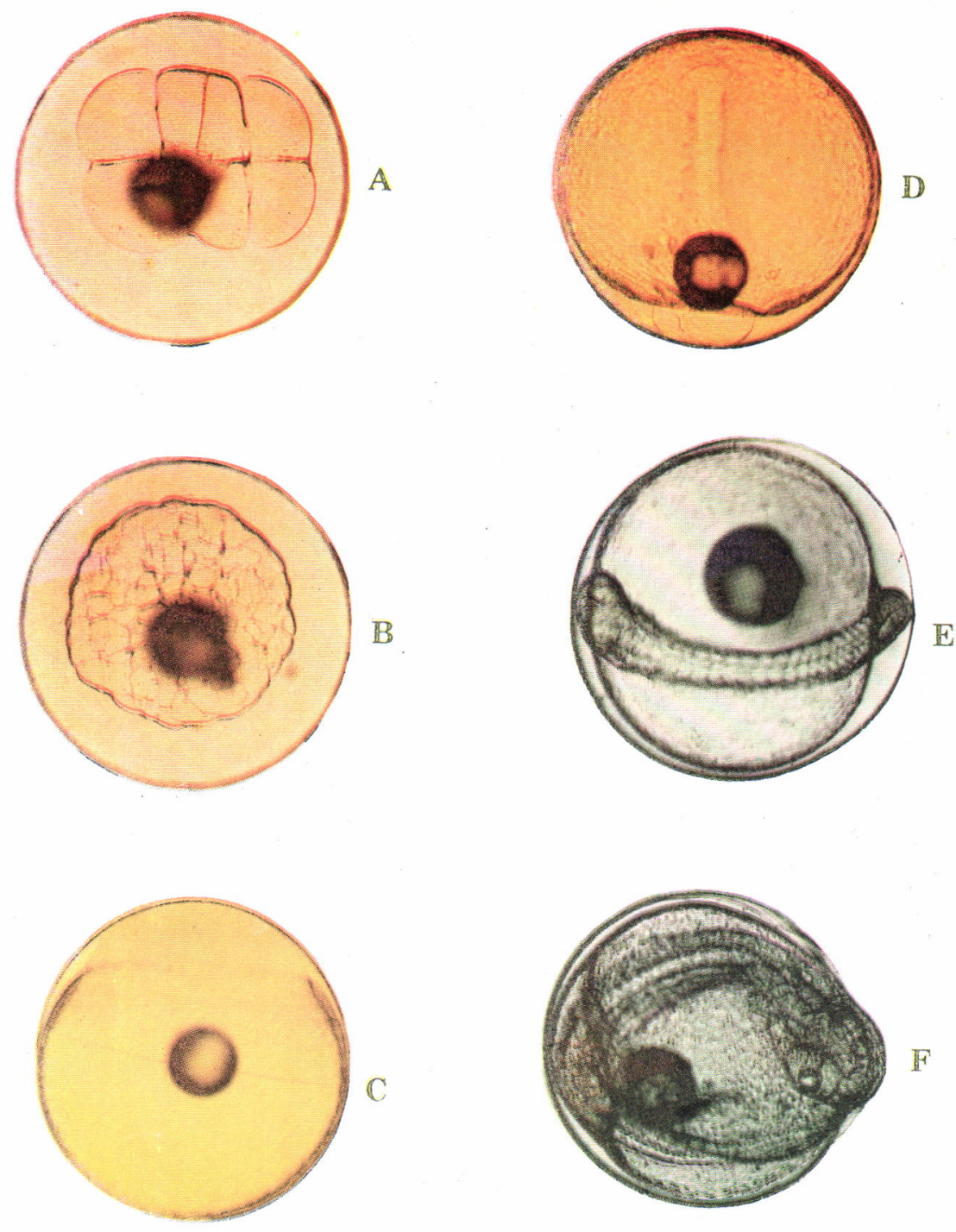

Gambar 1. Perkembangan telur ikan kerapu batik Epinephelus microdon.

A. Delapan sel; B. Morula; C. gastrula akhir; D. Neorula; E. Fase embrionic; F.Telur hampir menetas.

Figure 1. Egg development of grouper, Epinephelus microdon.

A. 8-cells; B. Morula; C. End phase of Gastrula; D. Neorula; E. Embryonic stage; F. Prehatching stage. 
dengan ukuran kuning telur $610 \mu \mathrm{m}$ sudah terserap sekitar 75\% dari volume kuning telur saat menetas. Pada larva umur ini penyerapan butir minyak masih relatif lambat di mana pada larva 16 jam SM dengan ukuran diameter butir minyak $167 \pm 5,5 \mu \mathrm{m}$ (Gambar 3).

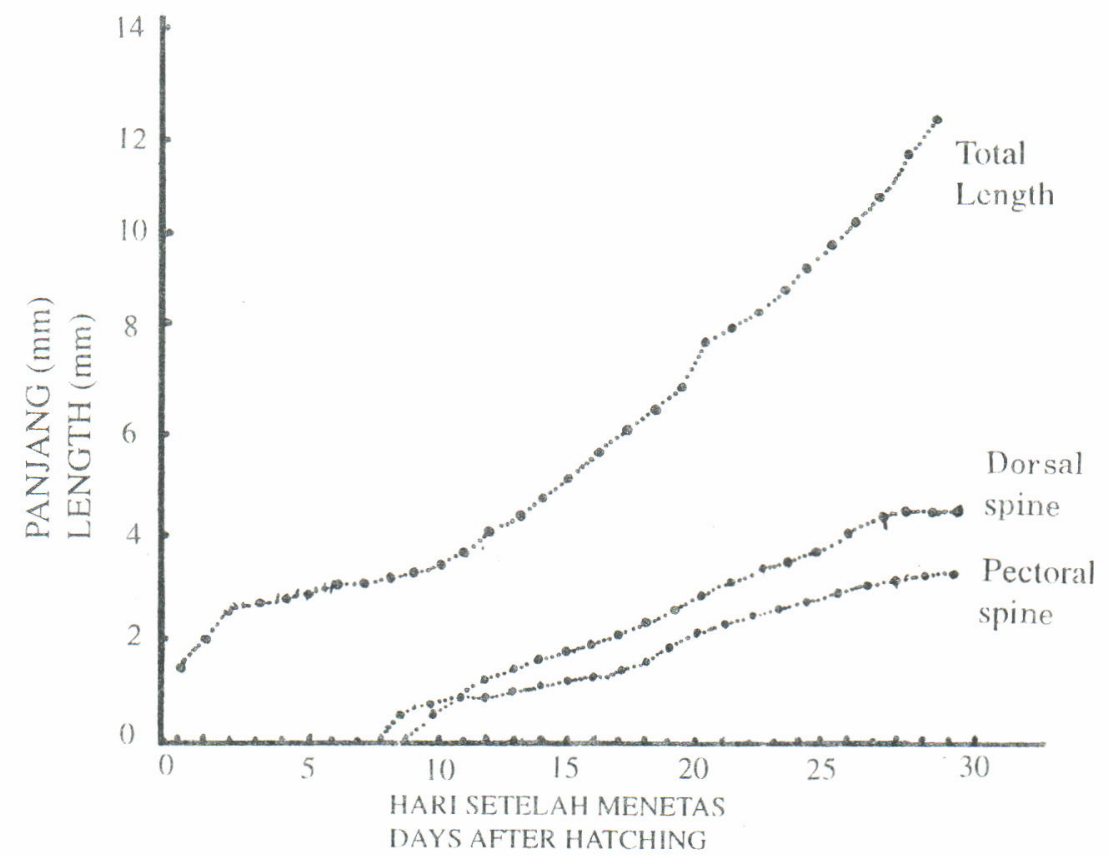

Gambar 2. Pertumbuhan panjang, duri punggung dan duri dada larva kerapu batik (Epinephelus microcton).

Figure 2. Growth of total length, dorsal spine and pectoral spine length of larval grouper (Epinephelus microdon).

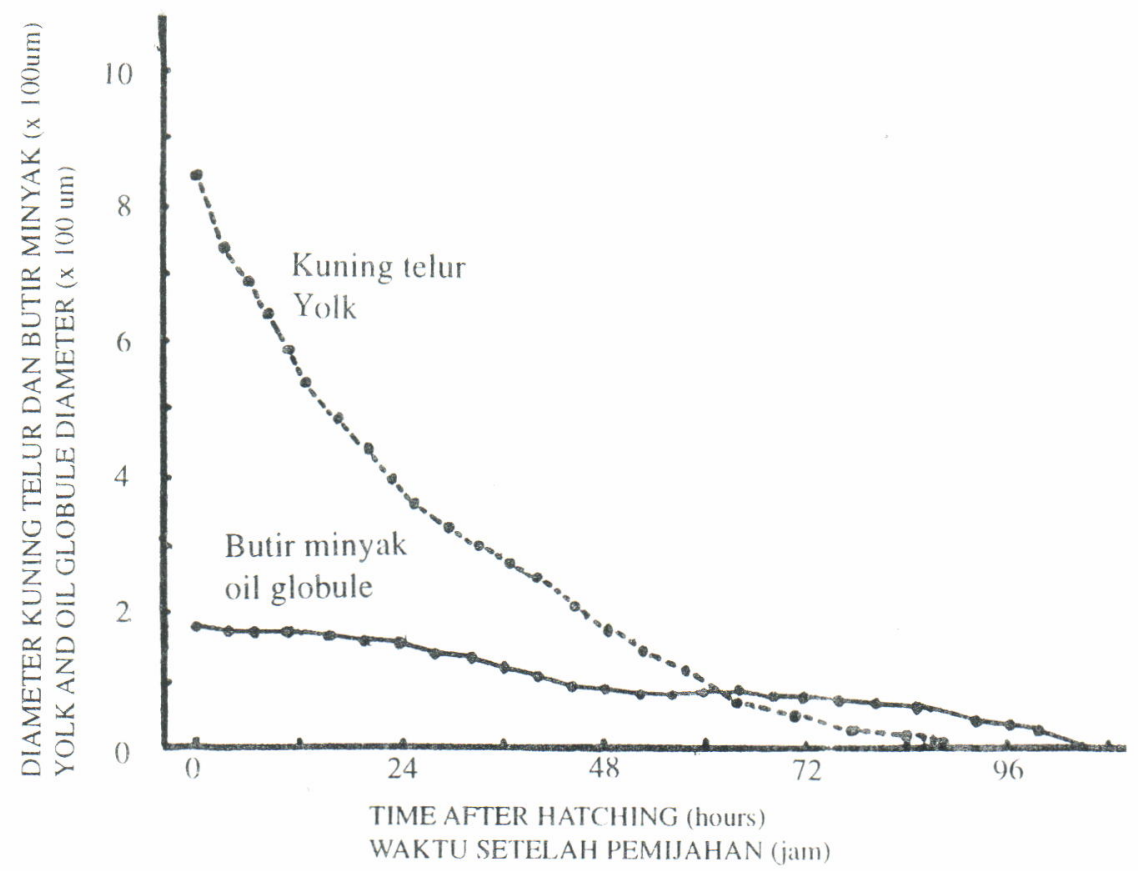

Gambar 3. Laju penyerapan kuning telur dan butir minyak pada larva kerapu batik (Epinephelus microdon).

Figure 3. Yolk and oil globule resorption in grouper (Epinephelus microdon) larvae. 


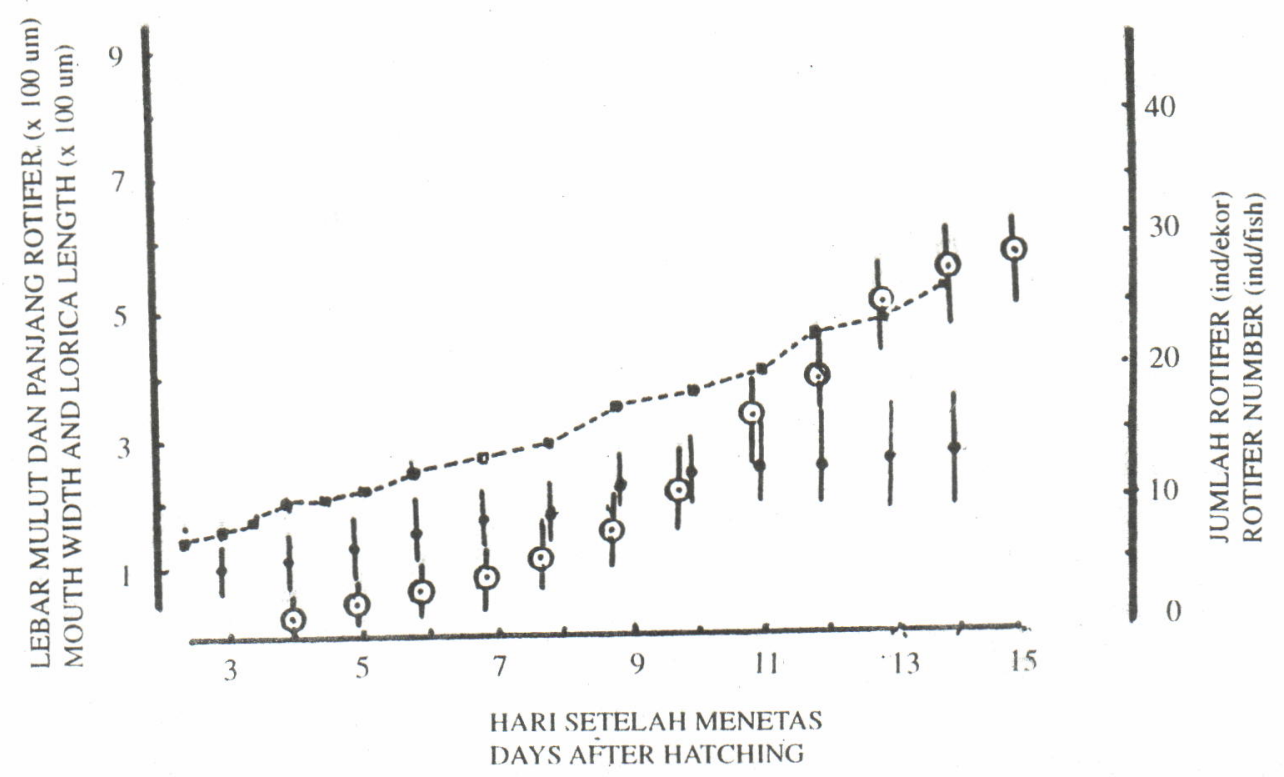

Gambar 4. Lebar mulut (segi empat buntu), panjang lorica rotifer yang dimakan (lingkaran buntu, rataan, kisaran) dan jumlah pakan (lingkaran berlubang) (rataan, kisaran) pada larva kerapu batik (Epinephelus microdon)

Figure 4. Mouth width (solid square), lorica length of rotifer eaten (solid circle, mean, range) and feeding amount (open circle, mean, range) in larval grouper (Epinephelus microdon).

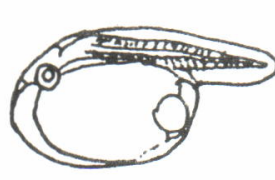

A

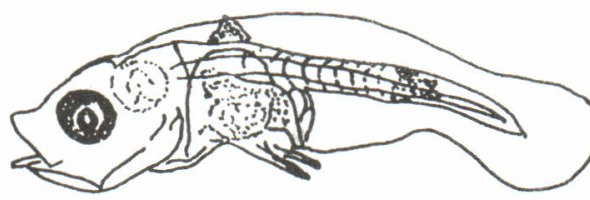

D
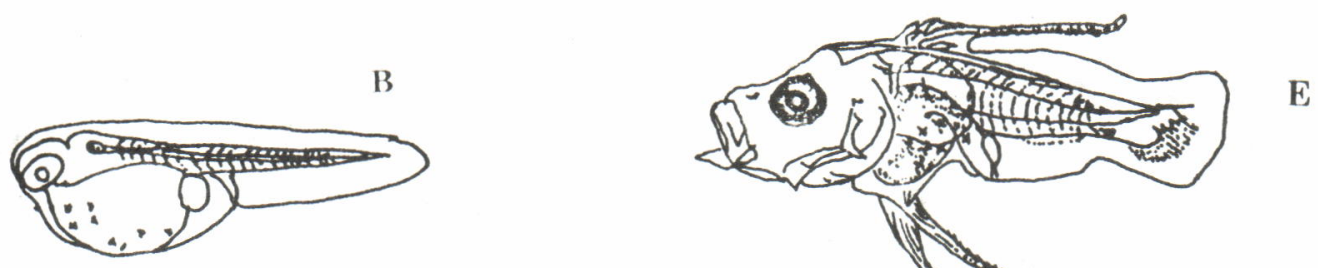

C
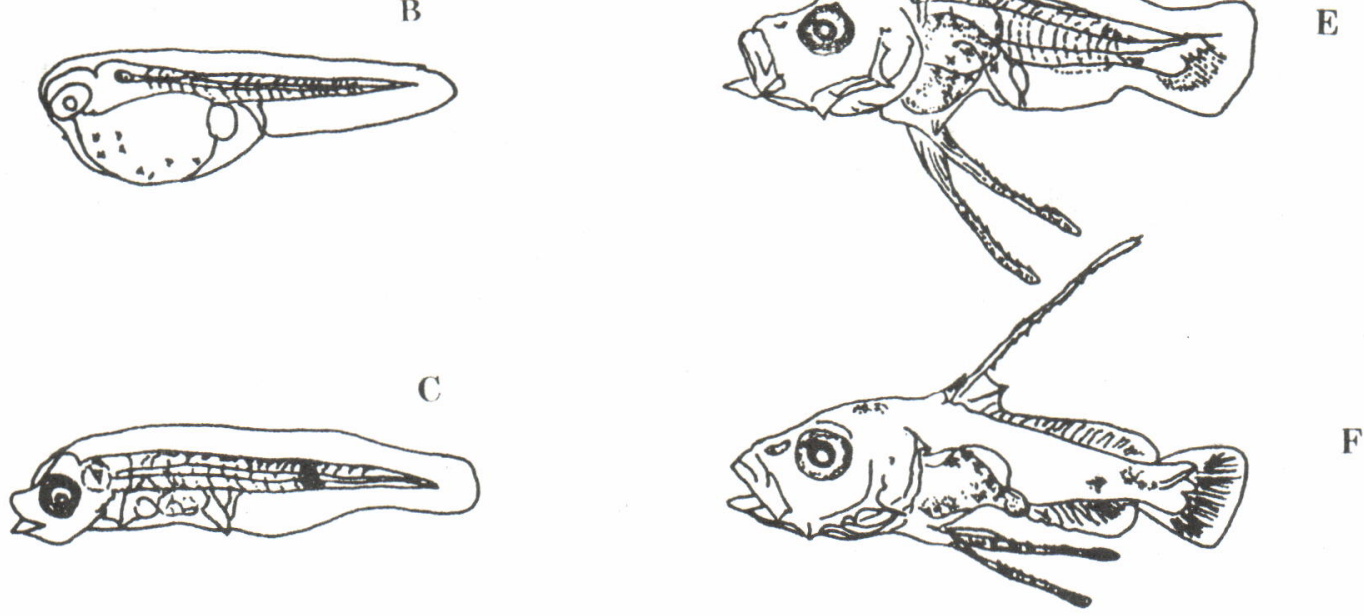

Gambar 5. Perkembangan larva ikan kerapu batik, E. microdon:

A. Larva baru menetas, B. Umur 1 hari, C. Umur 3 hari, D. Umur 6 hari, E. Umur 18 hari, F. Umur 25 hari.

Figure 5. Larval development of grouper, E. microdon:

A. Newly hatched, B. 1 day old, C. 3 days old, D. 6 days old, E. 18 days old, F. 25 days old. 
Larva pada 41 jam SM berameter $205 \mu \mathrm{m}$ tetapi belum terjadi pigmentasi. Pigmentasi mata mulai terjadi 43 jam SM dan lengkap pada 55 jam SM. Mulut sudah terbuka pada 52 jam SM dengan ukuran bukaan $152 \mu \mathrm{m}$. Pada larva D-2 kuning telur sudah terserap sampai dengan rataan ukuran $287 \pm 43,5 \mu \mathrm{m}$ pada 38 jam SM, sedangkan penyerapan butir minyak masih relatif lambat yaitu $93 \pm 4,8 \mu \mathrm{m}$ (38 jam SM).

Pada larva D-3 (Gambar 5C) mulai terbentuk melanofore (myomer) terkonsentrasi di sekitar lambung; alat sensor berupa kopulae terlihat satu pasang di bagian dorsal kepala. Pada 61 jam SM sebagian larva ( $20 \%$ sampel) mulai makan, semua larva masih mempunyai kuning telur dengan diameter 105-130 $\mu \mathrm{m}$ dan butir minyak terserap sampai ukuran $85 \pm 5,5 \mu \mathrm{m}$ ( 61 jam SM). Pada 67 jam SM semua larva masih mengandung kuning telur, pada 76 jam SM sebagian larva $(50 \%$ sampel) kuning telurnya sudah habis terserap.

Pada D.4 pagi (85 jam SM) kuning telur sudah habis terserap, dan saat ini penyerapan butir minyak relatif lebih cepat pada ukuran diameter $53 \pm 6,3 \mu \mathrm{m}$. Pada D-4 sore (91 jam SM) sebagian larva ( $50 \%$ dari sampel) butir minyaknya habis terserap dan lengkap semua terserap pada D-4 malam (95 jam SM). Dari hasil di atas dapat dikatakan bahwa penyerapan kuning telur berlangsung 76-85 jam dan butir minyak 91-95 jam SM. Sebagian larva $(80 \%)$ terlihat makan (terdapat rotifer di lambung) pada 85 jam SM, saat ini larva mempunyai ukuran lebar mulut $189 \pm$ $9,0 \mu \mathrm{m}$. Dari analisis isi lambung terdapat 0-6 ind. rotifer/larva dengan ukuran panjang rotifer (lorica) $80-150 \mu \mathrm{m}$ (rataan $95 \mu \mathrm{m}$ ).

Melanofore mulai menyebar ke ventral ekor saat larva berumur enam hari (Gambar 5E). Pada saat ini lambung sudah melipat, di mana pada umur sebelumnya berbentuk lurus. Pada larva umur delapan hari melanophore lebih banyak terbentuk pada pangkal ekor, sirip dada sudah terbentuk dan calon duri sirip punggung mulai terlihat. Duri sirip punggung (dorsal spine) mulai terlihat pada umur sembilan hari. Perkembangan morfologi larva kerapu batik adalah lebih cepat dibanding larva kerapu macan, di mana menurut Kohno et al. (1990) bahwa pada larva kerapu macan duri sirip punggung dan dada mulai terlihat pada umur 11 hari dan pada kerapu bebek (C. altivelis) sirip punggung dan dada mulai terlihat pada umur 11 hari (Slamet et al., 1996)
Gambar 4 memperlihatkan bahwa pada larva umur 3-12 hari, jumlah dan ukuran rotifer dalam lambung semakin besar dengan meningkatnya umur larva. Bila dilihat perbandingan ukuran rotifer dalam lambung dengan ukuran bukaan mulutnya, dapat dikatakan bahwa ukuran rotifer dalam lambung berkisar $40-70 \%$ dari ukuran lebar bukaan mulutnya. Menurut Kohno et al. (1990) pada larva kerapu macan (E. fuscoguttatus) umur 69 jam setelah menetas dapat memangsa pakan yang ukurannya $35-53 \%$ ukuran lebar bukaan mulutnya. Pada larva ikan bandeng (Chanos chanos) (Kohno et al., 1989), kakap putih (Kohno et al., 1986), beronang (Siganus guttatus) (Diani et al., 1990) dapat memangsa pakan dengan ukuran $20-80 \%$ lebar bukaan mulutnya dan pada kerapu bebek $(C$. altivelis) dapat memangsa pakan $20-60 \%$ ukuran lebar bukaan mulutnya (Slamet et al., 1996). Pada larva umur lebih dari 12 hari peningkatan jumlah rotifer dalam lambung relatif kecil dengan meningkatnya umur larva (Gambar 2). Hal ini dimungkinkan mulai umur 12 hari larva mulai membutuhkan jasad pakan yang ukurannya lebih besar dari rotifer karena bila dibanding dengan ukuran lebar mulutnya rotifer sudah terlalu kecil. Kesukaan makan larva dipengaruhi oleh ukuran, gerakan dan mudah terlihatnya jasad pakan oleh larva. Supriatna \& Kohno (1990) memberikan jasad pakan Artemia yang diperkaya pada kerapu macan (E. fuscoguttatus) mulai umur 12 hari.

Penyerapan kuning telur dan butir minyak sangat dipengaruhi suhu media. Lamanya penyerapan kuning telur dan butir minyak pada larva kerapu batik hampir sama dibanding larva kerapu macan. Menurut Kohno et al. (1990) pada larva kerapu macan kuning telur habis terserap pada 71-87 jam SM dan butir minyak pada 92,5. 94 jam SM (suhu media $27-29^{\circ} \mathrm{C}$ ). Pada larva ikan beronang (Siganus javus), kuning telur terserap habis pada 57 jam SM dan butir minyaknya pada 106 jam SM (Diani et al., 1990). Pada kerapu bebek kuning telur habis terserap pada 69-78 jam SM dan butir minyak pada 89-95 jam SM. Bila dilihat waktu antara pertama buka mulut sampai pertama kali makan adalah cukup lama (9-33 jam). Hal ini diduga karena belum sempurnanya fungsi mata yang ditandai dengan belum sempurnanya pigmentasi mata. Menurut Roger \& Westin (1981), kesuksesan makan pertama ditentukan juga oleh ukuran jasad pakan yang tersedia. Kebutuhan nutrisi dari luar harus cepat terpenuhi dalam waktu yang cukup sempit, 
apabila dalam waktu tersebut larva tidak cukup mendapat nutrisi dari luar, maka kemungkinan untuk sintasan nya sangat kecil. Keadaan seperti ini juga dilaporkan oleh beberapa peneliti pada jenis ikan lain seperti beronang tulis ( $S$. javus) (Diani et al., 1990) dan kerapu macan (Epinephelus fuscoguttatus) (Kohno et al., 1990) dan kerapu bebek (Slamet et al., 1996).

\section{KESIMPULAN}

1. Pemijahan alami ikan kerapu batik terjadi pada tengah malam jam 12.30.

2. Diameter telur $880-885 \mu \mathrm{m}$ dan butir minyak 170. $181 \mu \mathrm{m}$.

3. Waktu inkubasi telur pada suhu air $27-29^{\circ} \mathrm{C}$ berlangsung sekitar 18 jam 30 menit.

4. Larva yang baru menetas dengan panjang total sekitar $1.52 \mathrm{~mm}$ dan kuning telur berdiameter sekitar $843 \mu \mathrm{m}$.

5. Larva mulai buka mulut pada 61-85 jam setelah menetas (SM), kuning telur habis pada 75-85 jam SM dan butir minyak pada 91-95 jam SM.

6. Jumlah dan ukuran rotifer dalam lambung larva meningkat dengan meningkatnya ukuran dan umur larva.

\section{DAFTAR PUSTAKA}

Bouin, Y. And Y. Siaul. 1983. Observation on the female reproduction cycle and fecundity of three species of grouper (Epinephelus) from the Southeast Thunisia Seashore. Marine Biology, (73):211. 220

Budileksono, S. dan Y. Sofyan. 1993. Pemijahan alami ikan kerapu macan Epinephelus fuscoguttatus di bak terkontrol. Bulletin Budidaya Laut, (7):1-10.

Chen, F.Y., M. Chow, T.M. Chaw and R. Lim. 1977. Artificial spawning and larval rearing of the grouper, Epinephelus tauvina (Forskal) in Singapore, Singapore J. Pri. Ind. 5(1):1-21

Diani, S., B. Slamet, P.T. Imanto and H. Kohno. 1990. Resorption endogenous nutrition and initial feeding of the rabbitfish.Siganus javus. Bull. Pen. Perikanan Spec. Eds., 1:83-88.

Hardjamulia, A. 1988. Penyediaan induk untuk usaha pembenihan ikan budidaya air tawar. Seminar Nasional Pembenihan Ikan dan Udang, Bandung 5 6 Juli 1988.26p.
Heemstra, P.H. and J.E. Randall. 1993. FAO Species Catalogue, Vol. 16, Groupers of the world. FAO, Rome 382p, pl.XXXI.

Hamanto. S., S.Manabe, A.Kasuga and K. Nasoka. 1986. Spawning and early life history of grouper Epinephelus salmoides (Lacepede) in Laboratory. Tech. Rep. Farm. Fish., 15:143-155.

Huang, T.S., K.J. Lin, C.L. Yen, C.Y. Lin and C.L. Chen. 1986. Experiment on the artificial propagation of black spotted grouper, Epinephelus salmoides (Lacepede)-I, hormone treatment, ovulation of spawner and embrionic development. Bull. Taiwan Fish. Res. Inst., 40:241-248.

Hunter, J.R. 1980. The feeding behavior and ecology of marine fish larvae. In, Fish behavior and its use in the capture and culture of fishes,p 287-330.J.E. Bardach, J.J. Magnuson, R.C.May and M. Reinhart (eds), ICLARM, Manila, Philipines.

Hussain, N., M. Saif and M. Ukawa. 1975. On the culture of Epinephelus tauvina (Forskal). Kuwait Institute for Scientific Research, Kuwait. 12 p.

Hussain, N. and M. Higuchi. 1980. Larval rearing and development of the brown spoted grouper, Epinephelus tauvina (Forskal). Aquaculture, 19:339-350.

Kohno H., S. Hara and Y. Taki. 1986. Early larval development of the seabass Lates calcarifer with emphasis on the transition of energy sources. Nippon Suisan Gakkaishi, 54:1083-1091.

Kohno, H., M. Duray, A. Gallego and Y. Taki, 1989. Survival of larval milkfish, Chanos chanos, during changeover from endogenous to exogenous energy sources. In The second Asian Fisheries Forum, p. 437-440. R. Hirano and I. Hanyu (eds.), Asian Fisheries Society, Manila, Philipines.

Kohno, H., S. Diani, P. Sunyoto, B. Slamet and P.T. Imanto. 1990. Early developmental event assosiated with changeover of nutrient sources in grouper. Epinephelus fuscoguttatus larvae. Bull. Pen. Perikanan Spec. Eds., 1:51-64.

Lin, K.J., C.L. Yen, T.S. Huang, C.Y. Liu and C.L. Chen. 1986. Experiment of fry nursing of Epinephelus salmoides (Lacepede) and its morphological study. Bull. Taiwan Fish. Res. Isnt., 40: 219-240.

Maneewongsa, S. and T. Tattanon. 1982. Growth of larval and juvenile in the larval and fry production of the Seabass in Malaysia. Fisheries Research Research Institute, Glogor, Penang Malaysia. 24p.

Masume, S., N. Tezuka and K. Teruya. 1993. Embryonic and morphological development of larvae and juvenile coral trout, Plectropomus leopardus. J. Penelitian Budidaya Pantai, Terbitan Khusus 9(5):146-152. 
Mayunar, P.T. Imanto, S. Diani dan Yokokawa. 1991 Pemijahan ikan kerapu macan, Epinephelus fuscoguttatus. Bull.Pen.Perikanan, Spec. ed., 2:15-22.

Mayunar, B. Slamet dan S. Diani. 1993. Pematangan induk kerapu lumpur Epinephelus suillus dalam karamba jaring apung dengan berbagai perbandingan pakan ikan tembang dan cumi-cumi. J. Penelitian Budidaya Pantai, 9(5):42.48

Roger, B.A. and D.T. Westin. 1981. Laboratory studies on effect of temperature and delayed initial feeding on development of striped bass larvae. Trans. Am. Fish. Soc., 110:100-110.

Ruangpanit, N., P. Boonliptanon and J. Kongkumnerd. 1993. The proceeding of grouper culture. Held at Viva Hotel, November 30 - December 1. 1993. Songkhla, Thailand 32-44.

Supriatna, A. and H. Kohno. 1990. Larval rearing trial of the grouper. Epinephelus fuscoguttatus. Bull. Pen. Perikanan Spec. Eds.. 1:37-43.

Shapiro. 1987. Reproduction in grouper. p.295-326 In Tropical snapper and grouper, biology and of fisheries management. Westview/Bouler and London.

Slamet, B., P.T. Imanto, S. Diani dan T. Yokakawa. 1991. Pengamatan pada beberapa pemijahan ikan kakap putih, Lates calcarifer di Laboratorium. Bull. Pen. Perik., Spec. ed (2):3-14.

Slamet, B. dan S. Diani. 1993. Pengamatan pada musim, jumlah, rasio pembuahan dan rasio penetasan telur hasil pemijahan alami induk kakap putih Lates calcarifer di tangki pemeliharaan. J. Penelitian Budidaya Pantai. 9(5):111-119.
Slamet, B., Tridjoko, A. Prijono, T. Setiadarma dan K. Sugama. 1996. Penyerapan nutrisi endogen, Tabiat makan dan perkembangan morfologi larva kerapu bebek (Cromileptes altivelis). J. Penelitian Perikanan Indonesia, Vol.2, No.2, edisi khusus :13-21.

Sunyoto, P., Masril, A. Ismail dan S. Diani. 1993. Pemijahan rangsang dan perkembangan telur larva ikan kakap mata kucing, Psammoperca waigiensis. J. Pen. Budidaya Pantai, Eds. Khusus 9(5):146-152.

Tawada, S. 1989. Development of eggs, larvae and juvenile of Epinephelus microdon (Bleeker) reared in the hatchery. Suisanzoshoku, (37): 99-103.

Tridjoko, B. Slamet, D. Makatutu dan K. Sugama. 1966. Pengamatan pemijahan dan perkembangan telur ikan kerapu bebek Cromileptes altivelis pada bak secara terkontrol. J. Pen. Perikanan Indonesia, edisi khusus 2 (2) :55-62.

Tseng, W.Y. and S.K. Ho. 1979. Eggs development and early larval rearing of red grouper (Epinephelus akaara Temminck \& Schlegel). Quart. J. Thaiwan Mus., 32:209-219.

Tseng. W.Y. and K.F. Chan. 1985. On the larval rearing of the white spotted groupe, Epinephelus ablycephalus (Bleeker), with a description of larval development. J. World Maricult. Soc., 16:114-126.

Vanstone, W.E., L.B. Tiro, Jr.A.C. Villaluz, D.C. Barnes and C.E. Duenas. 1977. Breeding and larval rearing of milkfish Chanos chanos (Pisces: Chani(dae). SEAFDEC. Aqc. Dept. Tech. Report, 3:3-17.

Ukawa, M., M. Higuchi and S. Mito. 1966. Spawning habits and early life history of a serranid fish, Epinephelus akaara (Temminck et Schlegel). Japan J. Ichthyol.,13:156-161. 